The available vaccine will be distributed as evenly as possible throughout all the age groups. To achieve this children are being chosen for vaccination according to their month of birth. Details of those children to be vaccinated first will be found on p. 1055. The Medical Research Council is carrying out the selection, after first analysing all the registrations.

\section{Local Results}

The bulk of the English county health authorities, 30 out of the total 50 , recorded the registration of $21-40 \%$ of the eligible children; in seven counties $41-50 \%$ were registered, the highest figures being those returned by the Soke of Peterborough $(50 \%)$, North Riding of Yorkshire (49\%), and Northumberland $(48 \%)$. Three counties registered 11-20\% of those eligible, and ten counties $10 \%$ or under. The lowest were Worcester (1\%), Somerset (3\%), the Kesteven division of Lincolnshire $(4 \%)$, Nottingham $(6 \%)$, and Berkshire and Shropshire (each 7\%). London's figure is $31 \%$. In the English county boroughs 47 out of the 77 making returns recorded registration rates of $21-40 \%$; five rates of $41-50 \%$; and one, Exeter, a rate of $52 \%$, the highest in England. The other high rate was from York $(50 \%)$. At the other end of the scale, eleven boroughs had rates of $11-20 \%$, and 13 of $10 \%$ or under. The lowest rates were recorded by Bootle (1\%), Birkenhead and Smethwick (each $2 \%$ ), Sunderland (3\%), South Shields and Worcester (each $4 \%)$, Portsmouth (5\%), Dudley, Southport, and Wallasey (each $6 \%$ ), and Bath (7\%).

Wales shows, on average, a higher registration rate than England. Eleven, of the 17 local health authorities had rates of $31-50 \%$, and two higher, Carmarthen $55 \%$ and Glamorgan $52 \%$. The next highest rates were from Cardiff $(50 \%)$, Cardigan (48\%), and Pembroke (47\%). The lowest rates from Wales-but well above the English experience -were those from Anglesey and Flint (each 16\%) and Caernarvon (19\%).

Scotland had the highest percentage registration of all. Of the 31 county health authorities only two (Caithness $13 \%$ and Renfrew $15 \%$ ) had returns of less than $20 \%$, and only four others in the range $21-30 \%$. Eighteen Scottish counties registered $51-80 \%$ of those eligible, and four exceeded this figure-namely, Midlothian (91\%), Sutherland $(88.5 \%)$, Peebles $(83.9 \%)$, and Banff $(83.7 \%)$. The average for the Scottish county authorities is $57 \%$. The 24 large burghs in Scotland, with an average of $28.6 \%$, approximate closely to the figure for the whole of England and Wales $(29 \%)$. Here the highest figures were from Dunfermline $(76 \%)$, Ayr $(70 \%)$, Arbroath $(68 \%)$, and Hamilton (63.6\%). The lowest returns were from Clydebank (3.3\%), Kirkcaldy (4.5\%), Port Glasgow (7\%), Dumbarton (12\%), and Aberdeen (15\%). Acceptances from Edinburgh and Glasgow were $37.4 \%$ and $19.6 \%$ respectively.

The Northern Ireland Tuberculosis Authority celebrated its tenth anniversary on April 8 this year. In 194683 people in each 100,000 of the population of Northern Ireland died from tuberculosis, compared with slightly fewer in Scotland and about 55 per 100,000 in England and Wales. To-day the mortality rate is 14 per 100,000 . At the end of its first working year the Tuberculosis Authority found it had beds for 1,256 patients all occupied, and a waiting-list of 800 . A hospital on a 240-acre site at Brookhill, Co. Antrim, near Belfast, was planned to deal with 500 patients, but, as the Tuberculosis Authority expanded, the waiting-list for beds decreased until on January 31,1956 , only 94 patients were on it, so the plans for the hospital are now in abeyance. The mass radiography service carried out 32,000 examinations in 1948 and 100,000 in 1955 . The B.C.G. vaccine scheme was introduced in 1949 under which over 50,000 people have been tested. Twenty-eight clinics and eight tuberculosis hospitals, supplemented by wards in general hospitals, are spread throughout Northern Ireland to deal with tuberculous patients.

\section{Preparations and Appliances}

\section{A (SLEEVE-VALVE) NEEDLE FOR MAINTAINING AN OPEN VEIN DURING ANAESTHESIA}

Dr. J. A. SCANLon, anaesthetic registrar, West Suffolk General Hospital, writes : Several needles are available to anaesthetists to maintain an "open vein" during anaesthesia. It is suggested that the needle illustrated here overcomes many of the difficulties encountered with other types, a special advantage being the absence of any perishable components which deteriorate with both use and sterilization.

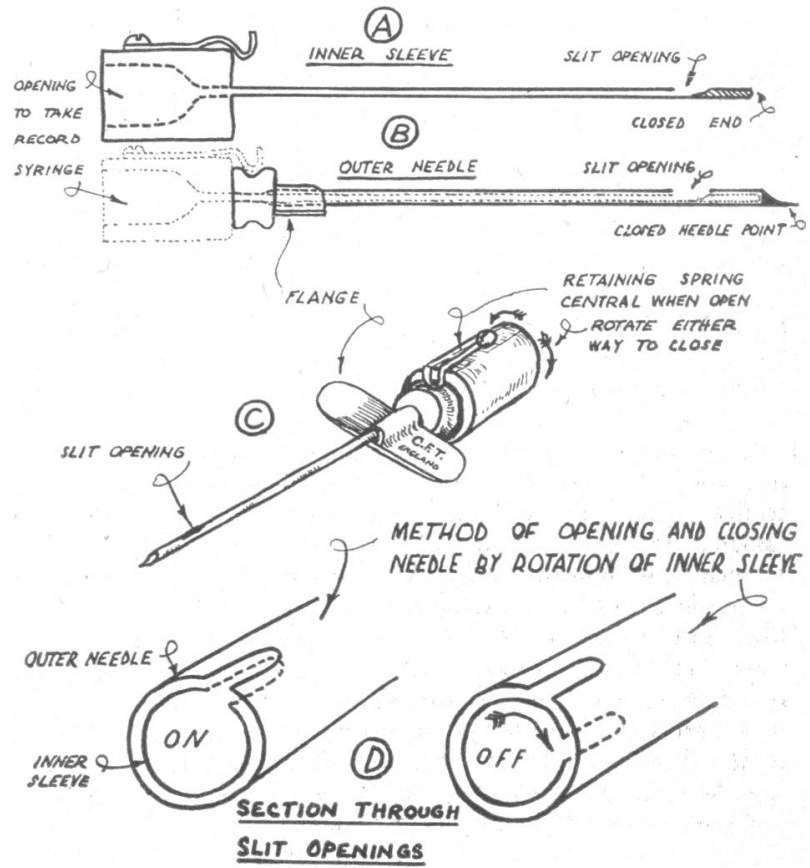

The Scanlon (sleeve-valve) needle.

The needle consists of two parts, an inner "sleeve" (A) and an outer needle (B). The inner sleeve has a slit which corresponds with a slit in the needle when the retaining spring is in the central position. Rotation of a syringe inserted into the sleeve (A) either way shuts off the hole, preventing blood entering and clotting the needle (D).

My thanks are due to Dr. H. Marcus Bird, consultant anaesthetist, for his encouragement, and to Charles $F$. Thackray, 38, Welbeck Street, London, W.1, who made the needle for me.

\section{Nova et Vetera}

\section{LINNAEUS AS PAEDIATRICIAN}

We are so familiar with the association of Linnaeus with botany that we are apt to forget he was also a physician with a remarkably wide range of interests, including pathology, chemistry, pharmacology, surgery, gynaecology, zoology, mineralogy, anatomy, physiology, veterinary medicine, and farming, just to mention only a few of his specialties. For 37 years (1741-78) he was professor of medicine at the University of Uppsala, whose Rector he was for some time. In a recent lecture Dr. Telemak Fredbäri ${ }^{1}$ has focused attention on the part played by Linnaeus in the infant welfare of his time. Much of his teaching on infant welfare was incorporated in a volume by itself, Nutrix noverca. Here problems which still trouble us are ventilated in a spirit

$$
{ }^{1} \text { Svenska LäkT., 1955, 52, } 2778 .
$$


reflecting the wisdom of an intellectual giant partially handicapped by ignorance of some of the knowledge of to-day. Linnaeus was a keen advocate of breast-feeding by mother rather than by wet-nurse, whose influence on the recipient of her milk might, he said, be very baneful. The wet-nurse who concentrated on developing her activities as such by stuffing herself with food and by "drinking bravely" was liable to become plethoric and ultimately melancholic, transmitting her emotions to her charge in the form of vomiting and convulsions. Whether she was crosseyed and bad-tempered or beautiful and cheerful, the babe she suckled would take his cue from her: witness the evil influence of their wet-nurses on Nero and Caligula. On surer ground comes the teaching that wet-nurses are apt to convey syphilis to their charges, and the advice that, if a wet-nurse has to be employed, she should be chosen by a doctor after he has examined her. This warning is rammed home by the detailed history of a syphilitic wetnurse. She infected her charge, who in turn passed the infection on to the mother, whence it spread to the father. Discharged when her syphilis was discovered, she entered the service of a baron and duly infected his child. Cow's milk was held to be even worse than the milk of a wetnurse, because a cow's stupidity might be transmitted to the baby. Suckling by the mother at regular intervals was not always to be recommended, since it might be more natural for the baby to choose its own time as it does when carried all day on its mother's back with one breast slung over her shoulder.

Linnaeus was the devoted father of seven children, and he lost one of them at the age of 3 years from whoopingcough, which he suspected was due to a living organism. During one of his journeys he learnt of a popular local remedy for whooping-cough-Ledum palustre. Whatever its intrinsic merits, Linnaeus found it worthy of a dissertation and inclusion in the Swedish pharmacopoeia of his time. Here it remained, and it was still there in the edition of 1879 , a reminder of the security of tenure of nostrums in a national pharmacopoeia once they have been admitted to it. For those of us who have blushed over our fear of the dark, it is comforting to learn that Linnaeus did not overcome this disability till he was 20 years old.

Claude Lillingston.

The population of Leeds is 507,200 , and $12 \%$ are of pensionable age. In 1951 a Joint Geriatric Services Committee was set up to consider the special problems of the geriatric hospitals in the city. The committee has now issued its First Survey of the Geriatric Services in the Leeds Area. This reports that since 1948 there has been a steady improvement in services for the aged, infirm, and mentally confused. The organization of this work is based on the statutory framework provided by the National Health Service and the National Assistance Acts, and there exists in addition several voluntary bodies which render personal services not easily carried out under statutory regulations. The main need is for accommodation for those who cannot look after themselves or be looked after in their own homes, and for domestic help which would enable more to stay in their homes. The Welfare Services Committee accommodate 657 in their hostels; voluntary societies 295 . The Haigh Hospital at Rothwell, which is for those who need no treatment but are not well enough to go home, has been a successful venture. The patients spend most of the day in communal sitting-rooms, so very few nurses are required. The geriatric units in the Leeds area had assigned 933 beds to chronic sick and elderly patients by the end of 1954 During that year 2,278 patients passed through the admission wards, where they underwent physical and psychological assessment, and 721 patients attended the follow-up clinic, where 128 new patients were seen. The units also accept for short periods patients who are normally nursed at home, to give melatives a holiday. The report of the committee provides a useful summary of the law relating to the care of old people.

\section{Correspondence}

\section{Potassium-losing Nephritis}

SiR,-We wish to congratulate the British Medical Journal on publishing the excellent annotation "Potassium-losing Nephritis" (Journal, April 21, p. 910). We consider, however, that the difficulties of differential diagnosis between true potassium-losing nephritis and primary aldosteronism were insufficiently emphasized. There are three steps in arriving at a correct diagnosis : (1) proof that the patient is deficient of potassium; (2) proof that the kidney is responsible for the potassium loss ; (3) decision whether the primary cause of the disorder is the adrenal or the kidney.

Steps (1) and (2) are readily solved by a potassium balance, but we consider that step (3) may be extremely difficult. We agree that the type of case with acidosis and a low plasma bicarbonate can almost always be confidently diagnosed as due to primary renal disease, especially if there is an associated specific renal disorder-e.g., the Fanconi syndrome or nephrocalcinosis. As you state, the cases showing a hypokalaemic alkalosis are less well defined. We consider that there are in fact four types : (1) primary aldosteronism without significant renal abnormality; (2) primary aldosteronism associated with a completely reversible secondary nephropathy due to prolonged potassium deficiency; (3) primary aldosteronism associated with severe irreversible renal disease; (4) true " potassium-losing nephritis" without any adrenal disorder. Naturally the boundaries between types 1,2 , and 3 are not sharply defined.

In the past year we have treated one case of type 1, one case of type 3 , and two cases of type 4 . The first case of primary aldosteronism to be described ${ }^{2}$ appears to have been of type 2 . The patient incorrectly diagnosed by Evans and Milne as "potassium-losing nephritis" has now been firmly diagnosed as primary aldosteronism associated with severe irreversible chronic pyelonephritis.

Obviously, the main practical point in diagnosis is the exclusion of primary aldosteronism, since types 1 and 2 are completely cured, and type 3 is improved by unilateral adrenalectomy. With present available techniques we consider that primary aldosteronism can in some cases only be excluded with absolute certainty either by a planned exploration of the adrenal glands or by necropsy. Our reason for being dogmatic in the diagnosis of our four patients is that both cases of primary aldosteronism have now had an adrenal adenoma successfully removed, and that both cases of "potassium-losing nephritis" have died of uraemia and been fully examined at necropsy.

Recent papers have been published giving suggestions regarding the differential diagnosis of potassium-losing states, often by investigators with no personal experience of primary aldosteronism. We have already found that this theoretical reasoning may be erroneous. The following methods have been recommended : $(a)$ In primary aldosteronism there is said to be great difficulty in raising the serum potassium to normal levels. In one of our patients hyperkalaemia was produced by a potassium intake of only $250 \mathrm{mEq}$. daily. (b) Determination of the salivary $\mathrm{Na} / \mathrm{K}$ ratio : this is of value, but may be misleading. In one of our cases of "potassium-losing nephritis" the ratio was considerably below the normal value, possibly because of secondary aldosteronism. (c) Peri-renal air insufflation with tomography : this is of great value if an adrenal tumour is demonstrated, but of no value if negative. In one of our cases of primary aldosteronism the combined size of the adenoma and unaffected portion of the gland was no greater than that of a normal adrenal gland. (d) Renal biopsy : this is most useful if the kidney is found to be normal or merely to show evidence of the nephropathy of potassium deficiency. It is obviously of no value in the differentiation of types 3 and 4 . (e) Estimation of blood 